\title{
Recommendations for the content and conduct of European League Against Rheumatism (EULAR) musculoskeletal ultrasound courses
}

\author{
E Naredo, ${ }^{1}$ J W J Bijlsma, ${ }^{2}$ P G Conaghan,${ }^{3} \mathrm{C}$ Acebes, ${ }^{4} \mathrm{P}$ Balint ${ }^{5} \mathrm{H}$ Berner-Hammer, ${ }^{6}$ \\ G A W Bruyn, ${ }^{7}$ P Collado, ${ }^{8}$ M A D'Agostino, ${ }^{9} \mathrm{~J} \mathrm{~J}$ de Agustin, ${ }^{10} \mathrm{E}$ de Miguel, ${ }^{11}$ \\ E Filippucci, ${ }^{12}$ W Grassi, ${ }^{12}$ A lagnocco, ${ }^{13}$ D Kane, ${ }^{14}$ J M Koski, ${ }^{15,16}$ B Manger, \\ L Mayordomo, ${ }^{17}$ I Möller, ${ }^{18} \mathrm{C}$ Moragues, ${ }^{19}$ E Rejón, ${ }^{17}$ M Szkudlarek, ${ }^{20}$ L Terslev, ${ }^{21}$ \\ J Uson, ${ }^{22}$ R J Wakefield, ${ }^{3}$ W A Schmidt ${ }^{23}$
}

For numbered affiliations see end of article

Correspondence to:

E Naredo, Calle Arturo Soria

259, $4^{\circ}$ A, 28033 Madrid, Spain; esnaredo@eresmas.com

Accepted 28 September 2007

Published Online First

5 October 2007

\begin{abstract}
Objective: To develop education guidelines for the conduct of future European League Against Rheumatism (EULAR) musculoskeletal ultrasound (MSUS) courses.

Methods: We undertook a consensus-based, iterative process using two consecutive questionnaires sent to 29 senior ultrasonographer rheumatologists who comprised the faculty of the 14th EULAR ultrasound course (June 2007). The first questionnaire encompassed the following issues: type of MSUS educational model; course timing; course curriculum; course duration; number of participants per teacher in practical sessions; time spent on hands-on sessions; and the requirements and/or restrictions for attendance at the courses. The second questionnaire consisted of questions related to areas where consensus had not been achieved in the first questionnaire, and to the topics and pathologies to be assigned to different educational levels.
\end{abstract}

Results: The response rate was $82.7 \%$ from the first questionnaire and $87.5 \%$ from the second questionnaire. The respondents were from 11 European countries. The group consensus on guidelines and curriculum was for a three-level education model (basic, intermediate and advanced) with timing and location related to the annual EULAR Congresses. The topics and pathologies to be included in each course were agreed. The course duration will be $20 \mathrm{~h}$. There will be a maximum of six participants per teacher and $50-60 \%$ of total time will be spent on practical sessions. There was also agreement on prerequisite experience before attending the intermediate and advanced courses.

Conclusion: We have developed European agreed guidelines for the content and conduct of EULAR ultrasound courses, which may also be recommended to national and local MSUS training programmes.

Within the last decade, an increasing number of rheumatologists worldwide have incorporated musculoskeletal ultrasound (MSUS) as a valuable imaging and research tool in their clinical practice.

The European League Against Rheumatism (EULAR) has supported 14 courses on MSUS since 1998. There have been introductory and advanced MSUS courses in different European countries under the auspices of the EULAR Standing Committee on Education and Training. European rheumatologists highly experienced in MSUS have comprised the faculty of these courses. Many of them chair and organise MSUS training for rheumatologists in their own countries.

In 2001, the first guidelines for performing MSUS in rheumatology were published by the EULAR Working Group for Musculoskeletal Ultrasound. ${ }^{1}$ These guidelines provided useful information on the technical basis for MSUS, equipment specifications, scanning methods and image acquisition along with the main pathological findings in each anatomical area.

Within the last 3 years, a number of relevant papers on MSUS education, curriculum and competency for rheumatologists have been published. $^{2-7}$ Brown et al produced an international interdisciplinary consensus on the specific indications, anatomic areas and knowledge and skills required by rheumatologists performing MSUS. ${ }^{4}$ Nevertheless, there is a wide variety of approaches to training in MSUS. ${ }^{8}$ Furthermore, there is a need for a standardised educational programme of efficient teaching and learning of MSUS for rheumatologists.

The purpose of this project was to develop education guidelines for future EULAR ultrasound courses. These could also be recommended to national and local MSUS training programmes as a formal educational model and curriculum for rheumatologists.

\section{METHODS}

\section{Study design}

The initial step involved a 2-month email-based forum on preliminary ideas for developing MSUS training guidelines, using a core group composed of the organisers of the recent past and future EULAR ultrasound courses. This preliminary approach included discussion on the following issues: (1) the desired model of MSUS education, (2) the theoretical and practical curriculum, (3) the proposed course schedule and duration and (4) the requirements and restrictions for attendance at the courses.

We then undertook a consensus process through two consecutive written questionnaires sent to the 29 senior ultrasonographer rheumatologists who comprised the faculty of the 14th EULAR ultrasound course that was held in Sitges, Spain, 10-13 June 2007. These faculty members were from 12 European countries (Denmark, 2; Finland, 1; 
France, 2; Germany, 4; Hungary, 1; Ireland, 1; Italy, 3; The Netherlands, 2; Norway, 1; Spain, 10; Switzerland, 1; UK, 1).

\section{Questionnaire design and content}

We developed the first questionnaire based on the issues discussed among the core group. This questionnaire was sent to the 29 rheumatologists who participated as faculty in the 14th EULAR ultrasound course, and they were asked to respond within 2 months. An explanation of the purpose of the exercise accompanied the questionnaire. After 4 weeks, e-mail reminders were sent to the non-responders.

The first questionnaire included 30 questions divided into 8 sections to be answered by ticking "yes" or "no" with space for additional comments. Participants were allowed to vote on more than one option for each section. The eight sections that comprised the first questionnaire included the following topics: MSUS educational model, course timing, course curriculum, course duration, number of participants per teacher in practical sessions, time spent on hands-on sessions, requirements, and/or restrictions for attendance at the courses. The educational model section offered four possibilities: two-level education, three-level education (eg basic, intermediate and advanced), two-level education and additional courses on selected advanced subjects, and two-level education and additional modular courses on specific anatomic areas and/or diseases or group of diseases. The course timing section offered four possibilities: ultrasound courses with timing and location closely related to the annual EULAR Congresses, ultrasound courses scheduled apart from the annual EULAR Congresses, the basic or the basic and intermediate courses with timing and location closely related to the annual EULAR Congresses and the advanced course at different time. The course curriculum section offered four questions about the main educational objectives of the courses (eg examination technique versus examination technique plus basic pathology for the basic course; MSUS research in rheumatology versus pathological findings in other specialities for the advanced course). The course duration section provided three possibilities: $20 \mathrm{~h}$ over 3 days, $24 \mathrm{~h}$ over 3 days, and $20 \mathrm{~h}$ over 2.5 days. With regard to the number of participants per teacher in practical sessions, three options (four, five or six participants) were given. The offered possibilities of time spent on "hands-on" sessions were $40-50 \%, 50-60 \%$ or $60-70 \%$ of the total duration of each course. Nine questions about different possibilities of requirements and/or restrictions for attendance at the courses were included in the last section.

The second questionnaire consisted of two parts. Firstly, seven questions were related to areas of non-consensus and comments supplied in the first questionnaire, to be answered by ticking "yes" or "no" with space for any additional comments. Secondly, it included a list of 22 topics and 29 MSUS pathologies to be assigned to different levels of education, together with space for any suggestions of other topics or pathologies not included in the provided list. Participants were allowed to vote on more than one option for each section. The second questionnaire and the results from the first questionnaire were sent by e-mail to the responders to the first questionnaire. They were asked to respond within 2 months and after 4 weeks, e-mail reminders were sent to the nonresponders.

\section{Analysis}

We calculated the percentage of respondents who answered yes and no to the questions included in each questionnaire. Group agreement with the issue under consideration was defined as agreement $\geqslant 65 \%$.

\section{RESULTS}

The response rate was $82.7 \%$ (24 out of 29) from the first questionnaire and $87.5 \%$ (21 out of 24) from the second questionnaire. The respondents were from 11 European countries (Denmark, 2; Finland, 1; France, 1; Germany, 2; Hungary, 1; Ireland, 1; Italy, 3; The Netherlands, 1; Norway, 1; Spain, 10; UK, 1). Because of the high percentage of respondents from one European country (Spain) with respect to the other countries, we calculated again the results for each question taking into account the answers from a maximum of four Spanish ultrasonographer rheumatologists. The four Spanish rheumatologists who had comprised the faculty of more EULAR ultrasound courses than the others were selected for this second analysis. The results of this separate analysis are only reported when they were different from the total group.

\section{Results from the first questionnaire round}

The total agreement for a three-level education model was $65.2 \%$. A total of $17.4 \%$ of the respondents voted for a two-level education model, $30.4 \%$ voted for two-level education and additional courses on selected advanced subjects and $26.1 \%$ voted for two-level education and additional modular courses on specific anatomic areas and/or diseases or group of diseases. Eight (33.3\%) respondents voted for two options. After analysing again the answers including only four Spanish respondents, $50 \%$ of the respondents voted for a three-level education model, $22.2 \%$ of the respondents voted for a two-level education model, $33.3 \%$ voted for two-level education and additional courses on selected advanced subjects and $22.2 \%$ voted for two-level education and additional modular courses.

Ultrasound courses with timing and location closely related to the annual EULAR Congresses was agreed by $87 \%$ of the respondents. However, there were comments on the possibility that future EULAR Congresses may take place in cities/ countries where there are no colleagues willing or able to organise the MSUS courses.

In all, $48.3 \%$ of the respondents voted that the basic course should include only ultrasound examination technique and $48.3 \%$ that it should also include basic pathological findings. A total of $74 \%$ of the respondents voted that advanced course should include MSUS research and methodology, an update on MSUS in rheumatology and technological developments, and $65.2 \%$ of the respondents voted that the advanced course should include MSUS uncommon findings in rheumatology as well as MSUS findings in other specialities.

The agreement on course duration was $48.3 \%$ for $20 \mathrm{~h}$ over 3 days, $43.5 \%$ on $24 \mathrm{~h}$ over 3 days and $13 \%$ on $20 \mathrm{~h}$ over 2.5 days.

A maximum of six participants per teacher, and ideally four or five participants per teacher, was voted by $100 \%$ of respondents.

With regard to time spent on "hands-on" scanning, more than $65 \%$ of the respondents voted for $50-60 \%$ of the total duration of each course.

In all, $61 \%$ of respondents agreed that there should be some restrictions to participating in EULAR ultrasound courses. Only $8.7 \%$ voted for restrictions in attending the basic course, $69.6 \%$ for restricting attendance at the intermediate course and $82.6 \%$ voted for restrictions on attending the advanced course. After considering only four Spanish respondents, $44.4 \%$ voted for 
some restrictions to participating in EULAR ultrasound courses, $5.5 \%$ for restrictions in attending the basic course, $61.1 \%$ for restricting attendance at the intermediate course and $72.2 \%$ voted for restricting attendance at the advanced course.

\section{Results from the second questionnaire round}

A proposal was made for three-level courses with timing and location closely related to the annual EULAR Congress if local organisers are willing and able to conduct such courses; as well, if future EULAR Congresses take place in cities/countries where there are no colleagues willing or able to organise the MSUS courses, the courses would be organised by another colleague in their own country/city. This was agreed by $95.2 \%$ of the respondents.

In all, $95.2 \%$ of the respondents voted that the basic course should focus on ultrasound examination techniques and basic pathology, the intermediate course should focus on a wide spectrum of rheumatologic pathology, and the advanced course should focus on current MSUS research in rheumatology, new technological developments, uncommon pathological findings in rheumatology, pathological findings in other specialities (such as nerve, ligament, muscle and sport-related lesions), and MSUS methodology.

The total agreement for course duration of $20 \mathrm{~h}$ for 3 days was $70 \%$.

The proposal was overwhelmingly agreed that there will be no restrictions on attending basic courses: however, the proposals that previous performance of $\geqslant 100$ MSUS scans before participating in an intermediate level course, and previous performance of $\geqslant 300$ MSUS scans before attending an advanced level course were agreed by $90.5 \%$ of the respondents.

Eight topics and five pathologies were assigned to the basic course by more than $70 \%$ of the respondents, 7 topics and 16 pathologies to the intermediate course and 8 topics and 9 pathologies to the advanced course (table 1).

In summary, the group consensus on guidelines and curriculum for future EULAR MSUS courses are outlined below.

\section{MSUS education model}

A three-level education model with basic, intermediate and advanced levels will be conducted.

\section{Course timing}

There will be three-level courses with timing and location related to the annual EULAR Congresses if local organisers are willing and able to conduct the courses. If future EULAR Congresses take place in cities/countries where there are no colleagues willing or able to organise the MSUS courses, another colleague can organise three courses (basic, intermediate and advanced)/simultaneously in their country/city. With this course timing, 2 years is the minimum time in which all three courses can be attended by trainees interested in MSUS. They would have a minimum of 1 year for practising between consecutive levels.

\section{Course curriculum}

Basic courses will focus on examination technique and will include some basic pathology. Intermediate courses will focus on a wide spectrum of rheumatologic pathology. Advanced courses will focus on current MSUS research in rheumatology, new technological developments, uncommon pathological findings in rheumatology, pathological findings in other specialities such as nerve, ligament, muscle lesions, sport related lesions and MSUS methodology (table 1).

\section{Course duration \\ A total of $20 \mathrm{~h}$ for 3 days.}

\section{Number of participants per teacher in practical sessions}

Ideally four or five, maximum six participants per teacher.

\section{Time spent on hands-on scanning}

In all, $50-60 \%$ of total time will be spent in practical training for all courses; $40-50 \%$ of total time will be theoretical teaching.

\section{Attendance at the EULAR ultrasound courses}

There will be no prerequisites for attending basic courses. Previous performance of $\geqslant 100$ musculoskeletal ultrasound scans is strongly recommended before participating in an intermediate-level course and previous performance of $\geqslant 300$ musculoskeletal ultrasound scans is strongly recommended before attending an advanced-level course.

\section{Certification}

The group voted for working towards certification of attendance and competency.

\section{DISCUSSION}

High-resolution MSUS has become an established imaging technique for evaluating periarticular and intra-articular structures involved in rheumatic diseases. ${ }^{9-11}$ In addition, ultrasound is a bedside tool for performing accurate and safe musculoskeletal injections. ${ }^{12}$

Within the last decade, several reports on the superiority of US over clinical evaluation and plain radiography for assessing early joint inflammatory and structural changes have directed MSUS applications in rheumatology towards early diagnosis, assessment of disease activity and monitoring of therapeutic response in patients with inflammatory arthritis. ${ }^{13-21}$

As a consequence of the recent technological development and increasing utility of MSUS, there is a great demand for appropriate education in this technique among rheumatologists worldwide. Since US is an operator-dependent imaging technique (mainly because of the intrinsic real time nature of US images acquisition) appropriate training is highly important to ensure skilled and safe use of MSUS by rheumatologists. ${ }^{22}{ }^{23}$

Sustained and extensive interest has occurred in attending EULAR ultrasound courses that have been organised over the last 9 years. Furthermore, several MSUS courses and workshops are offered by individual European national Societies of Radiology and Rheumatology and by Universities in many countries. In addition, MSUS is a compulsory part of rheumatology training in some European countries. However, until now there has been no agreed educational programme and curriculum on MSUS for European rheumatologists. We therefore aimed to develop guidelines on content and conducting MSUS courses for rheumatologists under the auspices of EULAR. These guidelines can also be followed by national and local societies and/or universities in order to standardise MSUS training across Europe. Standardisation of the MSUS education model is essential for validating the results of training in this technique.

We used a consensus method among European rheumatologists highly experienced in performing and teaching MSUS. They were asked to vote on different options regarding content 
Table 1 Musculoskeletal ultrasound (MSUS) course curriculum and pathology content for basic, intermediate and advanced levels

\begin{tabular}{|c|c|}
\hline Level & Content \\
\hline Basic & $\begin{array}{l}\text { Application, indications and limitations of MSUS in rheumatology. } \\
\text { Ultrasound physics and technology } \\
\text { Sonographic pattern of the different musculoskeletal tissues } \\
\text { MSUS artefacts and pitfalls } \\
\text { Standard sonographic scans of the shoulder, elbow, wrist and hand, hip, knee, ankle } \\
\text { Holding the probe and optimising the grey-scale settings of the sonographic system } \\
\text { Image documentation } \\
\text { Reporting ultrasound findings and diagnosis } \\
\text { Basic course pathologies } \\
\text { Joint synovitis } \\
\text { Joint effusion } \\
\text { Synovial hypertrophy } \\
\text { Bursitis } \\
\text { Tenosynovitis }\end{array}$ \\
\hline Intermediate & $\begin{array}{l}\text { Colour and power Doppler physics and technology } \\
\text { Application, indications and limitations of colour and power Doppler in rheumatology } \\
\text { Use of the colour and power Doppler settings } \\
\text { Colour and power Doppler artefacts } \\
\text { Use of colour and power Doppler to detect synovial and entheseal inflammation } \\
\text { Assessment and quantification of structural joint damage (bone, tendons, ligaments) } \\
\text { Sonographic-guided periarticular and articular injections } \\
\text { Intermediate course pathologies } \\
\text { Joint synovitis, synovial hypertrophy, tenosynovitis } \\
\text { Tendon calcification } \\
\text { Enthesopathy } \\
\text { Tendinosis } \\
\text { Paratenonitis } \\
\text { Tendon subluxation/luxation } \\
\text { Intrasubstance tendon lesions } \\
\text { Tendon impingement } \\
\text { Complete tendon tear } \\
\text { Partial tendon tear } \\
\text { Bone erosions } \\
\text { Osteophytes } \\
\text { Ganglia and cysts } \\
\text { Articular cartilage lesions } \\
\text { Peri- and intra-articular microcrystal deposit } \\
\text { Ligament, muscle, cartilage, fibrocartilage and synovial calcification }\end{array}$ \\
\hline
\end{tabular}

Advanced $\quad$ Optimisation of colour and power Doppler settings

Sonographic-guided musculoskeletal interventional procedures

Assessment and quantification of synovial, tenosynovial and entheseal inflammatory activity

Role of ultrasound in vasculitis

Evaluation of vessels and detection of vasculitis by sonography

Paediatric sonography: musculoskeletal sonoanatomy and pathological findings in rheumatic diseases

Uncommon sonographic pathological findings in rheumatology

MSUS technological development

3- and 4-dimensional MSUS

Update on MSUS in rheumatology

MSUS research and methodology

Advanced course pathologies

Peripheral nerve entrapment and lesions

Ligament lesions

Fibrocartilage lesions

Myopathy

Myositis

Muscle injury

Soft tissue masses

Loose bodies

Foreign bodies 
and conduct of MSUS courses. Controversial points were voted again in the next round after presenting the group replies from the previous round. The high response rate reflects their great motivation for MSUS education.

Because there was a higher number of respondents from one European country (Spain) than from the other countries, we analysed again the questionnaires taking into account only the answers from the four Spanish ultrasonographer rheumatologists who had participated as faculty in more EULAR ultrasound courses than their peers in order to avoid unbalanced influence from the country in question. After excluding the answers from six Spanish rheumatologists, the results did not change considerably.

The most controversial issue concerned how many levels of MSUS training should be included. Arguments for the threelevel education model (basic, intermediate and advanced) included that this would result in a higher competency achieved by trainees, more homogeneous groups in practical sessions in each course level, increased time for practical sessions in each course and a step-by-step training in MSUS. However, threelevel courses may be more difficult to organise and conduct, as well as more time consuming for participants and teachers than two-level courses. Nevertheless, the 14th EULAR ultrasound course consisted of three simultaneous basic, intermediate and advanced courses (10-13 June 2007, Sitges, Spain). This course was successfully carried out with a careful, pre-planned organisation.

With regard to the other educational models proposed, they were more frequently voted for than the two-level education model. The two-level education model plus additional courses on selected advanced subjects is quite similar to a three-level education model. The two-level education model plus modular courses on anatomic areas and/or diseases would lead to a higher number of courses than in the three-level model, increasing time and money spent on ultrasound education by trainees and trainers.

The total agreement for a three-level education model decreased from $65.2 \%$ to $50 \%$ after considering only four Spanish respondents. The six excluded Spanish rheumatologists voted for a three-level education model because most were involved as organisers of the 14th EULAR ultrasound course. Nevertheless, a three-level education model was agreed on by more respondents than a two-level education model (22\%), two-level education and additional courses on selected advanced subjects $(33 \%)$ and two-level education and additional modular courses $(22 \%)$.

With the three-level course timing, trainees can attend a course each year. They need a minimum of 2 years for attending basic, intermediate and advanced course and they have a minimum of 1 year for practising between consecutive levels. We consider that 2 years should be the minimal time necessary for achieving competency in MSUS

For the curriculum of the courses, we selected the principal topics and pathologies that have been considered relevant and appropriate for rheumatologic practice according to published data. ${ }^{6}$ Afterwards, they were assigned to the basic, intermediate and advanced level according to the results from the second questionnaire.

Since practical training under expert supervision is essential for appropriate MSUS learning, the courses should have a $50 \%$ to $60 \%$ of total time spent in practical, hands-on sessions and no more than six participants per tutor in such sessions.

Although the courses should be considered as a necessary starting point for developing and improving MSUS skills, training after courses by performing normal scans and diagnostic examinations is mandatory for consolidating the knowledge and skills provided during the courses. Then, a number of ultrasound examinations are recommended before attending intermediate and advanced courses.

Certification is desirable. Guidelines for certification of competency will be developed in cooperation with the EULAR Standing Committee on Education and Training, the EULAR Committee on Musculoskeletal Imaging, and with other European institutions.

In conclusion, we have developed European agreed guidelines for content and conducting EULAR MSUS courses, which will be also useful for standardising rheumatology MSUS training worldwide.

Author affiliations: ${ }^{1}$ Rheumatology Department, Hospital Severo Ochoa, Madrid, Spain; ${ }^{2}$ Rheumatology \& Clinical Immunology Department, University Medical Center Utrecht, The Netherlands; ${ }^{3}$ Academic Section of Musculoskeletal Disease, University of Leeds, Leeds, UK; ${ }^{4}$ Rheumatology Department, Fundación Jiménez Díaz, Madrid, Spain; ${ }^{5}$ Third General and Paediatric Rheumatology Department, National Institute of Rheumatology and Physiotherapy, Budapest, Hungary; ${ }^{6}$ Rheumatology Department, Diakonhjemmet Hospital, Oslo, Norway; ${ }^{7}$ Rheumatology Department, Medisch Centrum, Leeuwarden, The Netherlands; ${ }^{8}$ Rheumatology Department, Hospital Severo Ochoa, Madrid, Spain; ${ }^{9}$ Rheumatology Department, Ambroise Paré Hospital, UVSO University, Boulogne Billancourt, France; ${ }^{10}$ Rheumatology Department, Hospital Vall d'Hebron, Barcelona, Spain; ${ }^{11}$ Rheumatology Department, Hospital La Paz, Madrid, Spain; ${ }^{12}$ Rheumatology Department, Universitá Politecnica delle Marche, Ancona, Italy; ${ }^{13}$ Rheumatology Department, Sapienza University, Rome, Italy; ${ }^{14}$ Rheumatology Department, Adelaide and Meath Hospital, Tallaght, Dublin, Ireland; ${ }^{15}$ Rheumatology Department, Mikkeli Central Hospital, Mikkeli, Finland; ${ }^{16}$ Third Medical Department, University of Erlangen-Nürnberg, Germany; ${ }^{17}$ Rheumatology Department, Hospital de Valme, Sevilla, Spain; ${ }^{18}$ Rheumatology Department, Instituto Poal, Barcelona, Spain;

${ }^{19}$ Rheumatology Department, Hospital de Bellvitge, Barcelona, Spain; ${ }^{20}$ Rheumatology Department, University of Copenhagen, Hvidovre Hospital, Copenhagen, Denmark;

${ }^{21}$ Rheumatology Department, The Parker Institute, Frederiksberg Hospital,

Frederiksberg, Denmark; ${ }^{22}$ Rheumatology Department, Hospital de Mostoles, Madrid, Spain; ${ }^{23}$ Medical Centre for Rheumatology Berlin-Buch, Berlin, Germany

Competing interests: None declared.

\section{REFERENCES}

1. Backhaus M, Bumester GR, Gerber T, Grassi W, Machold KP, Swen WA, et al. Guidelines for musculoskeletal ultrasound in rheumatology. Ann Rheum Dis 2001:60:641-9.

2. Brown AK, ÖConnor PJ, Wakefield RJ, Roberts TE, Karim Z, Emery P. Practice, training, and assessment among experts performing musculoskeletal ultrasonography: Towards the development of an International consensus of educational standards for ultraonography for rheumatologists. Arthritis Rheum 2004;51:1018-22.

3. Usón J, Naredo E. Snap-shot of the ultrasound school of the Spanish society of rheumatology. Reumatismo 2005;57:1-4.

4. Brown AK, ÖConnor PJ, Wakefield RJ, Roberts TE, Karim Z, Emery P. Recommendations for musculoskeletal ultrasonography by rheumatologists: setting global standards for best practice by expert consensus. Arthritis Rheum 2005; 53:83-92.

5. Taggart A, Filippucci E, Wright G, Bell A, Cairns A, Meenagh G, et al. Musculoskeletal ultrasound training in rheumatology: The Belfast experience. Rheumatology 2006:45:102-5.

6. Brown AK, O'Connor PJ, Wakefield RJ, Roberts TE, Karim Z, Emery P. Practice training, and ultrasonography for rheumatologists: the development of specific competency based educational outcomes. Ann Rheum Dis 2006;65:629-36.

7. Filippucci E, Meenagh G, Ciapetti A, lagnocco A, Taggart A, Grassi W. E-learning in ultrasonography: a web based approach. Ann Rheum Dis 2007:66:962-5.

8. Woolf AD. Specialist training in rheumatology in Europe. Rheumatology 2002:41:1062-6.

9. Grassi W, Cervini C. Ultrasonography in rheumatology: an evolving technique. Ann Rheum Dis 1998;57:268-70.

10. Wakefield RJ, Gibbon WW, Emery P. The current status of ultrasonography in rheumatology. Rheumatology 1999;38:195-201.

11. Schmidt WA. Value of sonography in diagnosis of rheumatoid arthritis. Lancet 2001;357:1056-7.

12. Koski JM. Ultrasound-guided injections in rheumatology. J Rheumatol 2000:27:2131-8.

13. Kane D, Balint PV, Sturrock RD. Ultrasonography is superior to clinical examination in the detection and localization of knee joint effusion in rheumatoid arthritis. J Rheumatol 2003:30:966-71. 
14. Szkudlarek M, Court-Payen M, Jacobsen S, Klarlund M, Thomsen HS, Ostergaard M. Interobserver agreement in ultrasonography of the finger and toe joints in rheumatoid arthritis. Arthritis Rheum 2003:48:955-62

15. Karim Z, Wakefield RJ, Quinn M, Conaghan PG, Brown AK, Veale DJ, et al. Validation and reproducibility of ultrasonography in the detection of synovitis in the knee. Arthritis Rheum 2004;50:387-94.

16. Szkudlarek M, Narvestad E, Klarlund M, Court-Payen M, Thomsen HS, Østergaard M. Ultrasonography of the metatarsophalangeal joints in rheumatoid arthritis. Arthritis Rheum 2004;50:2103-12.

17. Wakefield RJ, Gibbon WW, Conaghan PG, ÖConnor P, McGonagle D, Pease C, et al. The value of sonography in the detection of bone erosions in patients with rheumatoid arthritis. Arthritis Rheum 2001;43:2762-70.

18. Terslev L, Torp-Pedersen S, Qvistgaard E, Kristoffersen H, Rogind H, DanneskioldSamsoe B, Bliddal H. Effects of treatment with etanercept (Enbrel, TNRF:Fc) on rheumatoid arthritis evaluated by Doppler ultrasonography. Ann Rheum Dis 2003;62:178-81.
19. Taylor PC, Steuer A, Gruber J, Cosgrove DO, Blomley MJK, Marsters PA, et al. Comparison of ultrasonographic assessment of synovitis and joint vascularity with radiographic evaluation in a randomized, placebo-controlled study of infliximab therapy in early rheumatoid arthritis. Arthritis Rheum 2004;50:1107-16.

20. Filippucci E, Farina A, Carotti M, Salaffi F, Grassi W. Grey scale and pewer Doppler sonographic changes induced by intra-articular steroid injection treatment. Ann Rheum Dis 2004;63:740-3.

21. Naredo E, Collado P, Cruz A, Palop MJ, Cabero F, Richi P, et al. Longitudinal power Doppler ultrasonographic assessment of joint inflammatory activity in early rheumatoid arthritis: predictive value in disease activity and radiological progression. Arthritis Rheum 2007;15:116-24.

22. Scheel AK, Schmidt WA, Hermann KG, Bruyn GA, D'Agostino MA, Grassi W, et al. Interobserver reliability of rheumatologists performing musculoskeletal ultrasonography: results from a EULAR "train the trainers" course. Ann Rheum Dis 2005;64:1043-9.

23. Naredo E, Möller I, Moragues C, de Agustín JJ, Scheel AK, Grassi W, et al. Interobserver reliability in musculoskeletal ultrasonography: results from a "teach-theteachers" rheumatologist course. Ann Rheum Dis 2006;65:14-9.

\section{Save your favourite articles and useful searches}

Use the "My folders" feature to save and organise articles you want to return to quickly-saving space on your hard drive. You can also save searches, which will save you time. You will only need to register once for this service, which can be used for this journal or all BMJ Journals, including the BMJ. 